\title{
SENSE AND SENSITIVITY IN NAMING
}

T he allocation of names to objects of all kinds, whether living or not, is essential for effective communication. This is a fundamental component of all languages, whether they are written or exist only as oral traditions. Any change in the name of an object will inevitably both hinder exchanges about it and also the retrieval of information from published works, databases, and today the worldwide web. There is consequently a social dimension to naming organisms as well as a scientific one.

Twenty-five years ago, I prepared a contribution on "Responsibility and Irresponsibility in times of nomenclatural change" (Hawksworth 1991). At that time, the concern was name changes made because of the nomenclatural rules then in force, rather than as a consequence of new scientific insights leading to improved classifications more accurately indicating relationships. Since that time, major changes have been made progressively through successive editions of the rules, now entitled the International Code of Nomenclature for algae, fungi, and plants (ICN; McNeill et al. 2012). There are now provisions for the conservation and rejection of species names, changing types of genera and species, designation of interpretative types (epitypes), suppression of publications, and for fungi the end of dual nomenclature and the prospect of lists of protected names. Provided that a case can be made and approved by the Nomenclature Committee for Fungi (NCF). there is no need to change familiar names for nomenclatural reasons alone. Unfortunately, following this procedure is both lengthy and timeconsuming, so on occasion researchers impatient to have work published make changes in names without trying that route. The prospect of lists of protected names which are safeguarded against any other potentially competing names, however, promises to obviate the need to use the NCF route in many cases.

Twenty-five years on, there is a new cause for concern, and one that is growing. Molecular phylogenetics has revitalised systematic mycology over the last 1015 years. It has become an exciting and vibrant field of research, enabling existing classifications to be tested and revised, and previously unsuspected relationships to be discovered. I have enjoyed the opportunity of being involved personally in this revolution. When translating the clades emerging from such analyses into classifications, however, there is an issue of which to give formal scientific names, and the rank that should be introduced. In making that decision, it is important to recognize that there will never be any universal rules across biology as to what degree of molecular difference or age of a clade has to be interpreted as meriting a name at a particular rank. There is also no reason to suggest that the size of a genus is a consideration as suggested by Taylor (2014). There are, for example, 57 genera of flowering plants estimated to contain at least 500 described species, the largest of which is Astragalus (milk-vetches), with over 3,270 species (Frodin 2004), and amongst the insects, the genus Agrilus (jewel beetles) also has over 3,000 species (Bellamy 2010). There are also sound arguments for accepting paraphyletic taxa in some cases (Hörandl 2006).

In making a decision about what to formally name, and at what rank, it is important not to forget that the primary purpose of allocating names to organisms is communication, and that that purpose may not always be compatible with representing the finest divisions that can be argued for on a molecular basis. This is a particularly sensitive issue with respect to genera, where some familiar and extremely widely used generic names have been replaced by suites of new or previously synonymized names. The issue has become of such concern in Agaricomycetes, that 17 distinguished and experienced systematic mycologists (Vellinga et al. 2015) produced guidelines on what should and should not be recognised as a genus. In the lichenforming family Teloschistaceae, no less than 52 new generic names have been proposed over the last few years by adopting such narrow concepts; this causes immense confusion, and not unsurprisingly, many are rapidly moving into synonymy (Jaklitsch et al. 2016). This is not to argue that all newly introduced generic "splits" are to be avoided, especially if they are linked to life-style differences and can be separated morphologically, such as Saproamanita (Redhead et al. 2016).

The situation is somewhat different at the rank of species, as so-called cryptic

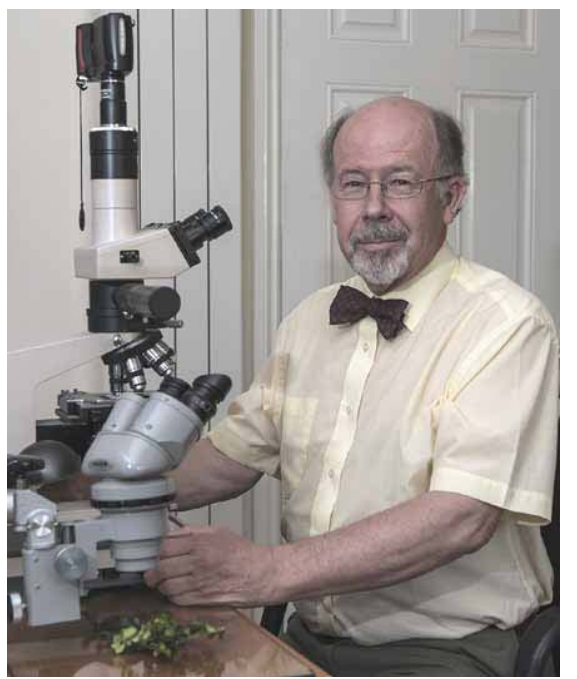

species may need to be recognised in, for example, assessments of conservation status and pathogenicity. In some cases it may be necessary for those without access to molecular methods, especially ecologists and field workers, to increasingly record species complexes or aggregates as is the practice in some plant "species", such as Euphrasia offinalis aggr. or Rubus fruticosus aggr. Personally, I continue to follow what I term the pragmatic species concept: "species are groups of individuals separated by inheritable character discontinuities and which it is useful to give a species name to" (Hawksworth 1996)!

The purpose of this Editorial is to remind those introducing new classifications of the importance of being sensitive to their user communities, which in some cases are becoming increasingly frustrated and disenchanted with some current practices (Jordan 2016). I am also reminded of an IUBS Executive Committee meeting in the late 1980s when a senior and influential Italian ecologist stated that they no longer funded taxonomic research as more research led to more name changes.....

Bellamy C L (2010) Genus Agrilus: a Checklist of World Buprestoidea. http://www.fond4beetles. com/Buprestidae/WorldCat/Genera/Agrilus. htm

Frodin DG (2004) History and concepts of big plant genera. Taxon 53: 753-776.

Hawksworth DL (1991) Responsibility and irresponsibility in times of nomenclatural change. In: Improving the Stability of Names: needs and options (Hawksworth DL, ed.): $13-$ 16. [Regnum Vegetabile no. 13.] Königstein: Koeltz Scientific Books. 
Hawksworth DL (1996) Microbial collections as a tool in biodiversity and biosystematic research. In: Culture Collections to Improve the Quality of Life (Samson RA, Stalpers JA, van der Mei D, Stouthamer AH, eds): 26-35. Baarn: Centraalbureau voor Schimmelcultures.

Hörandl E (2006) Paraphyletic versus monophyletic taxa-evolutionary versus cladistic classifications. Taxon 55: 564-570.

Jaklitsch W, Baral H-O, Lücking R, Lumbsch HT (2016) Ascomycota. In: Syllabus of Plant Families: AdolfEngler's Syllabus der Pflanzenfamilien (Frey W, ed.) 1(2): 1-322. Stuttgart: Borntraeger Science Publishers.

Jordan M (2016) Molecularly based generic and species concepts and the field mycologist. IMA Fungus 7: (42).
McNeill J, Barrie FR. Buck WR, Demoulin V, Greuter W, et al. (eds) (2012) International Code of Nomenclature for algae, fungi, and plants (Melbourne Code) adopted by the Eighteenth International Botanical Congress Melbourne, Australia, July 2011. [Regnum Vegetabile no. 154.] Königstein: Koeltz Scientific Books.

Redhead SA, Vizzini A, Drehmel DC, Contu C (2016) Saproamanita, a new name for both Lepidella E.-J. Gilbert and Aspidella E.-J. Gilbert (Amaniteae, Amanitaceae). IMA Fungus 7: (119)-(129).

Taylor JW (2014) Appropriately sized genera and appropriately ranked higher taxa. IMA Fungus 5: (1)-(2).

Vellinga ES, Kuyper TW, Ammirati J, Dejardin DE, Halling RE, et al. (2015) Six simple guidelines for introducing new genera of fungi. IMA Fungus 6: (65)-(68).

\section{David L. Hawksworth Editor-in-Chief, IMA Fungus (d.hawksworth@nhm.ac.uk; d.hawksworth@kew.org)}

PS: Any comments submitted concerning this Editorial will be considered for publication in a future issue of IMA Fungus. 